\title{
Bir Tekstil Fabrikasının Karbon Ayak İzinin Değerlendirilmesi
}

\author{
Yusuf Başoğul $^{1 *}$, Taha Tuna Göksu², M. Fırat Baran ${ }^{3}$

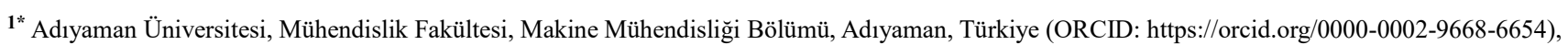 \\ ybasogul@adiyaman.edu.tr \\ ${ }^{2}$ Adıyaman Üniversitesi, Mühendislik Fakültesi, Makine Mühendisliği Bölümü, Adıyaman,Türkiye (ORCID: https://orcid.org/0000-0003-2028-3362), \\ tgoksu@adiyaman.edu.tr \\ ${ }^{3}$ Siirt Üniversitesi, Ziraat Fakültesi, Biyosistem Mühendisliği, Siirt,Türkiye (ORCID: https://orcid.org/0000-0002-7657-1227), firat.baran@siirt.edu.tr
}

(İlk Geliş Tarihi 08 Ekim 2021 ve Kabul Tarihi 15 Aralık 2021)

(DOI: 10.31590 /ejosat.1006302)

\begin{abstract}
ATIF/REFERENCE: Başoğul, Y., Göksu, T.T., Baran, M.F. (2021). Bir Tekstil Fabrikasının Karbon Ayak İzinin Değerlendirilmesi. Avrupa Bilim ve Teknoloji Dergisi, (31), 146-150.

\section{$\ddot{O} z$}

Artan sera gazlarının çevreye etkisinin araştırılmasında en önemli faktör ve parametrelerden biri karbon ayak izidir. Dünya genelinde kişi bazlı azaltılmaya çalışılan bu parametre için fabrikalar ve özellikle de tekstil fabrikaları büyük önem arz etmektedir. Bu çalışmada, Adıyaman ilinde faaliyet gösteren bir tekstil fabrikasının karbon ayak izi değerlendirilmesi yapılmıştır. Verileri toplama ve değerlendirme tekniklerinin başında gelen ve çalışmaya uygunluğu da gözlemlenen Tier-1 metodu karbon ayak izi değerlendirmesinde kullanılmıştır. Tekstil fabrikasının servis aracı/dizel tüketimi, doğal gaz tüketimi, elektrik tüketimi, atık su bazlı faktörleri sırasıyla 5,475 lt/yıl-dizel, 55,200 m³ , 456,000 kWh/yıl, 4,900 m³ olarak hesaplanmıştır. Belirtilen veriler tekstil fabrikasının 300 gün için çalıştığı farz edilip reel verilerle hesaplanmıştır. Tier-1 metoduna uygun olarak yapılan hesaplamalar sonucunda tekstil fabrikasının karbon ayak izi 297,343 ton $\mathrm{CO}_{2} /$ yıl olarak hesaplanmıştır. Burada en önemli etkiyi elektrik tüketimi gösterirken en az etkiyi ise atık su göstermiştir. Türkiye'deki tekstil fabrikalarının karbon ayak izi değerlendirmesine önemli bir ışık tutan bu çalışma tekstil fabrikalarının karbon ayak izinin sera gazlarındaki önemli derecede olan etkisini göstermektedir.
\end{abstract}

\section{A Case Study on the Assessment of Carbon Footprint of a Textile Factory}

\begin{abstract}
The crucial factor in the future of increasing greenhouse gases is the carbon footprint. It is of great importance for these factories around the world. In this study, the carbon footprint of a textile factory operating in Adiyaman province was evaluated. Tier-1, which is one of the primary data collection and techniques, was used in the footprint evaluation. The service vehicle/diesel consumption, natural gas consumption, electricity consumption, wastewater of the textile factory were calculated as 5,475 lt/year-diesel, 55,200 $\mathrm{m}^{3}, 456,000$ $\mathrm{kWh} /$ year, 4,900 $\mathrm{m}^{3}$, respectively. The carbon footprint of the textile factory was calculated as 297,343 tons $\mathrm{CO}_{2} / \mathrm{year}$ in the programming made by the Tier-1 method. Here, the most important effect is electricity consumption, while the least effect is caused by wastewater. This study, which sheds important light on the carbon footprint assessment of textile factories in Turkey, shows a large amount of greenhouse gases at the carbon footprint of textile factories.
\end{abstract}

Keywords: Carbon Footprint, Textile Factory, Tier 1, Greenhouse Gas 


\section{Giriş}

İnsanoğlu ihtiyaçlarını karşılamada daima doğal kaynaklardan faydalanmıştır. Bugün nüfusun artmasıyla birlikte, bireylerin bilinçsizce ve sürdürülebilirlikten uzak tüketim anlayışı nedeniyle dünyamız üzerindeki doğal kaynaklar azalmakta ve yakın bir gelecekte tükeneceği varsayılmaktadır (Baran ve et al., 2019). Enerji üretimi, tüketimi ve bunun sonucu olan karbon ayak izi gibi parametreler günümüzün en önemli konusu olup üretilen karbon ayak izi miktarının etkisi günümüz dünyasının en önemli yap1 taşı haline geldiği aşikârdır. Enerji üretilirken en önemli parametre küresel isınmaya sebep olan faktörlerden biri olan sera gazıdır ve giderek bu gazın salınımı da artmaktadır. En yaygın sera gazı salınan miktar ve küresel 1sınma üzerindeki toplam etkisi bakımından insan faaliyetleri tarafindan yayılan karbondioksit $\left(\mathrm{CO}_{2}\right)^{\prime}$ 'dir (Brander, 2012; Oruk and Baran, 2021). Ayrıca salınımın artmasına neden olan parametrelerin başında fosil yakıtlı hidrokarbonların tüketimi gelmektedir. Küresel ısınmaya karşı oluşturulan KYOTO protokolü ve Paris İklim anlaşması kapsamında, küresel 1sınmaya sebep olan karbon ayak izi hesaplaması büyük önem kazanmış olup bu konuda birçok alanda karbon ayak izi değerlendirilmesi yapılmıştır. Bunların en önemlileri gıda, tekstil vs gibi fabrikalar yer almaktadır (Başoğul \& Göksu, 2021).

Tekstil sektöründeki enerji, ekolojik ve Karbon Ayak İzi (KAİ) genel hatlarıyla değerlendirilmiştir (Athalye, 2016). Tekstil sektöründe karbon ayak izi üzerine yapılan çalışmada elde edilen sonuçlara göre sera gazına en büyük etkinin elektrik ve termal enerjisinden kaynaklandığı gözlemlenmiştir (Bevilacqua et al., 2011).

İsveçte yaşam döngüsü değerlendirme analizinde (LCA) \%50 pamuk ve $\% 50$ polyesterden oluşan bi model atık için 3 farklı geri dönüşüm tekniği belirlenmiştir. Elde edilen sonuçlara göre, yanmanın en yüksek küresel 1sınma potansiyeline etkisi olduğunu ve birincil enerji kullanımına sahip olduğunu göstermektedir. Verilere göre malzemenin yeniden/geri kullanım süreci, 8 ton $\mathrm{CO}_{2}$ /ton kaybını engellemekle birlikte ve 164 gigajoule (GJ)/ton tekstil enerji tasarrufu sağlamıştır. Belirtilen geri dönüşüm süreçleri düzgün entegre edildiği durumda 1 ton tekstilden kaybının karşılığ 1 olan 10 ton $\mathrm{CO}_{2}$ olan ve 169 GJ enerji kaybı engellemiş olur (Zamani et al., 2015).

Paris Anlaşması kapsamında 2050 yılına kadarki süreçte Yaşam Döngüsü Değerlendirmesi kullanılarak Fransadaki tekstil üreticilerinin KAİ'si hesaplanmıştır. Buna göre bir Fransız vatandaşının KAI'si bir yılda 442 kilograma kadar ulaştığ gözlemlenmiştir. Amaç ise KAI'yi 6 faktör azaltmak (74 kg $\mathrm{CO}_{2}$ eq/kişi/yıllık tekstil) ve bu kapsamda şunlar denenmiştir: düşük karbonlu elektrik karışımına sahip bir ülkede enerji üretim süreçlerinin kurulması, satılmamış mallardan kaçınmak, ekotasarım yaklaşımlarını uygulayarak ve yeniden kullanım veya geri dönüşüm ile ömrünü tamamlamış ürünlerin değerini artırmaktı. Elde edilen sonuçlara göre belirtilen süreçler uygulandığında KAİ miktar1 $43 \mathrm{~kg} \mathrm{CO} /$ yıl 'a düşürülmüştür(Payet, 2021).

Tekstil sektöründe ekolojik ve KAİ'yi azaltmak için birçok çalışma yapılmıştır. Bu kapsamda önemli çalışma ve sonuçlardan biri de 3R tekniğinin önerilmesidir. 3R tekniği veya KAI azaltma yönteminin içeriği şu şekildedir: 1. Geri dönüşüm veya yeniden kullanım yolu (burada önemli olan nokta ulaşım sektöründeki kullanımıdır) 2. tekstil çamurunun besin değeri de dahil olmak üzere tekstil endüstrilerinden kaynaklanan atık yönetimi 3 . tarımsal sulamada kullanılacak atık su şeklindedir (Rathore \& Singh, 2019).

Çin'de tekstil sektöründe üretilen saf pamuklu gömleklerin KAI'’ye dair yapılan araştırma sonuçlarına göre ortalama saf pamuklu gömleğin KAI'si $8.771 \mathrm{kgCO}_{2}$ olarak elde edilmiştir. Bulunan KAİ'nin $0.347 \mathrm{kgCO}_{2}$ si doğrudan olmakla birlikte geri kalan ve büyük çoğunluğunu oluşturan kısmı ise dolaylı yoldan olduğu gözlemlenmiştir. Saf pamuklu gömleğin üretimdeki süreçte KAI'ye en büyük etkiyi elektrik tüketiminin yaptığını gözlemlemişlerdir (Wang et al., 2015).

Tekstil atıklarının geri dönüşümü sağlanarak KAİ'yi düşürme çabaları da tekstil sektöründe KAİ'yi olabildiğince azaltabilmek için önemlidir. $\mathrm{Bu}$ kapsamda SIMAPRO 7.3 versiyonu kullanılarak KAI' ye etkisi araştırılmıştır (Muthu et al., 2012).

Tekstil sektöründe ürün üretim süreçlerinde KAI'ye etkinin yüksek olduğu gözlemlendiği gibi üretim proseslerinde deri ile temas eden ürünün sağlığa direkt etkisinin de olduğu aşikârdır. Bu proseslerdeki tehlikeli çözücülerin ortadan kaldırılması, çevre dostu kimyasalların kullanımı, toksik boyaların kullanılmaması ve yaş işlemede suyun yeniden kullanımı gibi faktörler hem KAİ'yi azaltırken hem de ekolojik bir dönüşüm sağlamada önemli etki yapmaktadır (Jain, 2017).

Çin'de 2016 yılı verilerine göre altıncı en büyük enerji tüketim kapasitesinin tekstil sektöründe olduğu gözlemlenmiştir. $\mathrm{Bu}$ veri beraberinde sera gazlarını gündeme getirmektedir. Elde edilen sonuçlara göre bu alanda sera gazlarının ana kaynağının kömür olduğu anlaşılmıştır. Kömürden sonra, Doğu Çin, Orta Çin ve Kuzey Çin gibi bölgelerdeki elektrik şebekelerinden gelen elektrik tüketimi de önemli derece etki yaptığı gözlemlenmiştir. Eğer, eğirme, dokuma ve 1slatma gibi işlemlerde kullanılan önlemlerin arttırılması durumunda 2030 y1lı tahmin senaryosuna göre \%34.3 daha az olacağ gözlemlenmiştir (Huang et al., 2017).

Sera gazı emisyonlarının yüksek olduğu tekstil sektörünün 2014-2017 yılları arasındaki etkisinin araştırıldığı çalışmanın sonuçlarına göre 2014 yılındaki karbon ayak izinin 42867.72 $\mathrm{tCO}_{2} \mathrm{e}$ olduğu görülmüştür (Akhtar et al., 2017).

Çin'de yünlü ve pamuklu kumaşların üretim aşamasındaki KAİ'si araştırıldığında ortaya çıkan sonuçlara göre saf yünlü kumaşların, karışımlı yün-polyester kumaşların ve pamuklu kumaşların KAI'si $14.07 \mathrm{kgCO}_{2} \mathrm{e} / \mathrm{kg}, 13.55 \mathrm{kgCO}_{2} \mathrm{e} / \mathrm{kg}$ ve 5.34 $\mathrm{kgCO}_{2} \mathrm{e} / \mathrm{kg}$ olduğunu hesaplamışlardır. Elde edilen diğer sonuçlara göre dokumadan önce boyanan kumaşın KAİ'sinin sonradan boyanana göre $\% 70.8$ da yüksek olduğu ayrıca düz dokuma işlemi ile üretilen kumaşın KAİ'sinin rib ile üretilene göre \%76.2 daha fazla olduğunu gözlemlemişlerdir (Yan et al., 2016).

Literatürden de anlaşıldığ 1 üzere bu çalışmada enerji tüketen proseslerin en önemlilerinden biri olan tekstil sektöründeki karbon ayak izine dair bir araştırma yapılmıştır. Bu bağlamda verilen örnek Adıyaman ilindeki önemli bir tekstil üretim fabrikasıdır. Bütün veriler fabrikanın 300 gün çalıştığı farzedilerek fabrikadan alınmıştır. Sunulan araştırma makalesinin Türkiyede tekstil fabrikalarının karbon ayak izi değerlendirmesine önemli bir 1şık tutacağ öngörülmektedir.

\section{Materyal Ve Yöntem}

$\mathrm{Bu}$ araştırma makalesinde Adıyaman ilinde tekstil üretimi yapan bir fabrikanın reel verileri kullanılmıştır. Belirtilen tekstil fabrikasının KAİ'ye neden olan faktörleri; elektrik tüketimi, 
doğal gaz tüketimi, servis aracı, atık su ve endüstriyel atık şeklindedir. Fabrikadaki üretim bandında meydana gelen endüstriyel atıklar karbon emisyonuna önemli bir etki yapmaktadır. KAİ, herhangi bir ürünün üretim hattı boyunca ve bazen de ömrünü tamamlanma süreci olduğu durumdaki geri kazanımı ve ortadan kaldırılmasıyla ilgili olarak karbondioksit ve diğer sera gazı emisyonlarının toplam miktarını ifade etmektedir (JRC, EC, 2007). KAİ hesaplanmasında ve değerlendirilmesinde kullanılan uygun metod: Hükümetler arası İklim Değişikliği Paneli (IPCC)'nin oluşturduğu Tier yaklaşımlarıdır. IPCC programı vasitasiyla hesaplanan emisyonlar belirsizlikler de katılarak "'Ulusal Sera gazı Emisyon Envanteri Raporu'ndaki" programdaki Tier 1, Tier 2 ve Tier 3 yaklaşımlarına göre değerlendirilmektedir. (Eggleston et al., 2006).

Sunulan araştırma makalesinde; Adıyaman ilinde üretim yapan önemli bir tekstil fabrikasının KAİ belirlenmesi amacıyla hesaplanıp doğal gaz tüketimi, servis aracı, atık su ve endüstriyel atık emisyonlar değerlendirilmiş ve bunların küresel ısınmaya etkisi vurgulanmıştır. $\mathrm{CO}_{2}, \mathrm{~N}_{2} \mathrm{O}$ ve $\mathrm{CH}_{4}$ gibi gazlar karbon ayak izi hesaplamalarında önemli bir yer teşkil etmektedir. Belirtilen gazların küresel ısınma potansiyelleri (KIP) IPCC Raporuna göre sirasiyla 1, 28 ve 265 'tir (Stocker vd. 2014). IPCC' nin hesaplama metodolojisine uygun formül $(C F=A D \times E F)$. Belirtilen formülde CF (karbon ayak izi); elektrik tüketimi, doğal gaz tüketimi, gidilen yol sonucu harcanan dizel veya benzin miktarı vs. gibi faaliyetler sonucu herhangi bir fabrikanın veya işletmenin atmosfere yaydığı hava kirleticilerinin karbondioksit eşdeğeri $\left(\mathrm{CO}_{2} \mathrm{e}\right)$ türünden miktarını, $\mathrm{AD}$ (faaliyet verisi); bir proses tarafından tüketilen veya üretilen yakıt veya maddelere ilişkin veriyi, EF (emisyon faktörü); belirli bir kirleticinin birim değeri (hacim, kütle, zaman, alan vb.) için ortalama emisyon miktarını göstermektedir. Çizelge 1 de tekstil üretim bandının yıl bazında olan faaliyetlerin verileri gösterilmiştir. Alınan veriler fabrikanın 2020 yılındaki tüketim miktarıdır. Verilen değerler tekstil fabrikasının yıllık ortalama 300 gün çalıştığı durum için geçerlidir.

\section{Çizelge 1. Tekstil Fabrikasının Faaliyetlerine Dair Veriler}

\begin{tabular}{|c|c|c|}
\hline Faaliyet Verisi & Birim & Miktar \\
\hline Elektrik Tüketimi & $\mathrm{kWh} / \mathrm{y} 1 \mathrm{l}$ & 456,000 \\
\hline Dizel Tüketimi & lt/yıl-dizel & 5,475 \\
\hline Atık su & $\mathrm{m}^{3}$ & 4,900 \\
\hline Doğal Gaz & $\mathrm{m}^{3}$ & 55,200 \\
\hline
\end{tabular}

Çizelge 1'deki verilerden anlaşıldığı üzere faaliyet verileri 4 ana başlıkta sıralanmıştır. Bunlar, elektrik, doğal gaz ve dizel tüketiminden kaynaklı ve ayrıca atık sudan oluşmaktadır. İhmal edilebilecek düzeydeki enerji kayıpları hesaplamalara katılmamıştır.

\section{EMISYON FAKTÖRLERİ}

Emisyon faktörlerinin hesabında Elektrik Tüketimi/Toplam Elektrik Tüketimi (ET veya TET), Yol (Servis aracının dizel veya benzin tüketimi), Atık Su/Toplam Atık Su Miktarı (AS veya TASM), Endüstriyel Atık (EA) gibi faktörler başlıcalarıdır. Karbon ayak izi hesabında kullanılan Emisyon faktörlerini değerlendirme-hesaplama metodu ve bu faktörlerin denklemleri aşağıda belirtildiği gibidir.

ET: 2018 yılı Enerji Bakanlığı'nın eletkrik tüketimi için emisyon faktörü verisi kullanılmıştır.

Elektrik $\mathrm{CO}_{2}$-e $=\mathrm{EF}\left(\mathrm{CO}_{2}\right) \mathrm{X}$ TET $(\mathrm{KWh})$

Ulaşım-Yol: Kullanılan yakıt dizeldir. 2011 yılındaki Avrupa standardında sera gazının hesabı kullanılmıştır.

Dizel- $\mathrm{CO}_{2}-\mathrm{e}=\mathrm{EF}\left(\mathrm{CO}_{2}-\mathrm{e}\right)$ x Tüketim (lt)

AS: Atık suyun bileşiminde kirleticilere ek olarak hidrokarbonlarda bulunmakta olup bunları niteliği farklılık taşımaktadır. Atom numaralarına ve derişimlerine göre kimyasal formülü $\mathrm{C}_{10} \mathrm{H}_{19} \mathrm{O}_{3} \mathrm{~N}^{\prime}$ dir.

$\mathrm{CO}_{2}$ hesaplama:

$\left(\mathrm{C}_{10} \mathrm{H}_{19} \mathrm{O}_{3} \mathrm{~N}+25 / 2 \mathrm{O}_{2} \longrightarrow \mathrm{NH}_{3}+10 \mathrm{CO}_{2}+8 \mathrm{H}_{2} \mathrm{O}\right)$

$\mathrm{CO}_{2}$-Atık su $=(($ KOİ (Kimyasal Oksidasyon İhtiyac1) $)$ - $($ KOİ(Yönetmelik x $\left(\mathrm{CO}_{2} \mathrm{~mol} / \mathrm{O}_{2} \mathrm{~mol}\right) \times 10 / 12.5$ x TASM

$\mathrm{CH}_{4}$ hesaplama:

AS içinde barındığı veya çözünmüş olarak ya da uğradığı prosesler sonrasında $\mathrm{CH}_{4}$ gazı da meydana gelmektedir.

$\mathrm{EF}\left(\mathrm{CH}_{4}\right)$ atık su $=11,5 \mathrm{~g} \mathrm{CH}_{4} / \mathrm{kg} \mathrm{KOİ-} \mathrm{(Gülhan} \mathrm{et} \mathrm{al.,} \mathrm{2018)} \mathrm{x}$ $\operatorname{KIP}\left(\mathrm{CH}_{4}\right)$

Emisyon $\mathrm{CO}_{2}-\mathrm{e}\left(\mathrm{CH}_{4}-\right.$ atı $\left.\mathrm{ku}\right)=\mathrm{EF}\left(\mathrm{CH}_{4}\right) \mathrm{AS} \times \mathrm{TASM}$

$\mathrm{N}_{2} \mathrm{O}$ hesaplama:

$\mathrm{N}_{2} \mathrm{O}$ (diazotoksit-nitrozoksit) ön arıtımdan sonra veya biyolojik arıtım prosesi geçtikten sonraki değerlendirilen AS çamurunda diğer gazlara göre oluşmaktadır. Burada İSKİ çalışmasında kullanılan örnek 9 tesisin değerleri baz alındı. Buna göre

TASM: 499,619,300 $\mathrm{m}^{3}$

Toplam oluşan $\mathrm{N}_{2} \mathrm{O}$ emisyonu $698,085,000 \mathrm{CO}_{2}$-e gr ise

$\mathrm{EF}\left(\mathrm{N} 2 \mathrm{O}\right.$ atık su $\mathrm{CO}_{2}$-e) $=1,397 \mathrm{~g} / \mathrm{m}^{3} \mathrm{CO}_{2}$-e (Gülhan et al., 2018) olarak bulunmuştur.

Emisyon $\left(\mathrm{N}_{2} \mathrm{O}\right.$ atık su $\left.\mathrm{CO}_{2}-\mathrm{e}\right)=\mathrm{EF}\left(\mathrm{N} 2 \mathrm{O}\right.$ Atık su $\left.\mathrm{CO}_{2}-\mathrm{e}\right)$ x TASM

EA: EF $\left(\mathrm{CO}_{2}\right.$-e)çöp $=\mathrm{EF}\left(\mathrm{CH}_{4}\right)($ Turhan \& Tolunay, 2017) x KIP x Toplam Katı Atık Miktarı (TKAM) (kg)

$=128.9 / 193.6$ X 25 X TKAM kg)=16,645 kg/kg X TKAM $(\mathrm{kg})$

Verili denklemlere göre hesaplanan Emisyon faktörleri Çizelge 2' de verilmiştir.

\section{Çizelge 2. Emisyon faktörleri}

\begin{tabular}{|c|c|}
\hline Faaliyet verisi & Emisyon Faktörü \\
\hline Elektrik tüketimi & $381.2 \mathrm{~g} / \mathrm{KWh}$ \\
\hline Servis arac1-Dizel Tüketimi & $2,900 \mathrm{~g} / \mathrm{lt}$ \\
\hline Doğal gaz & $1,814.971 \mathrm{~g} / \mathrm{m}^{3}$ \\
\hline Atık su & $1,520.897 \mathrm{~g} / \mathrm{m}^{3}$ \\
\hline Endüstriyel atık & $16,645 \mathrm{~kg} / \mathrm{kg}$ \\
\hline
\end{tabular}




\section{Bulgular Ve Tartışma}

Tekstil üretimi yapan fabrikanın faaliyet verileri Çizelge 1'de ve ayrıca bu fabrikanın emisyon faktörleri de Çizelge 2' de verilmiştir. Yukarıda belirtilen IPCC' nin formülüne uygun şekilde hesaplanan KAI'’nin yıllık verilerine karşın nihai sonuçları ise Çizelge 3'te aktarılmaktadır. Nihai sonuçların bütün değerlendirmedeki etkisinin yüzdelik olarak gösterimi Şekil 1'de verilmiştir.

Çizelge 3. Bir tekstil fabrikasının KAI miktarı

\begin{tabular}{|l|l|}
\hline Karbon Ayak İzi Kaynakları & Karbon Ayak İzi $\left(\mathbf{C O}_{2} \mathbf{e} / \mathbf{y} \mathbf{l}\right)$ \\
\hline Elektrik tüketimi & $173,827,000$ \\
\hline Servis aracı & $15,877,500$ \\
\hline Atık su & $7,452,395.3$ \\
\hline Doğal Gaz & $100,186,399.2$ \\
\hline Toplam & 297,343 ton \\
\hline
\end{tabular}

KAİ açısından tekstil firması değerlendirildiğinde $\mathrm{CO}_{2} \mathrm{e} / \mathrm{y} 1 \mathrm{l}$ olarak en yüksek elektrik tüketiminde görülmüştür. Elektrik tüketimini doğal gaz tüketimi takip ederken en düşük KAİ $\left(\mathrm{CO}_{2} \mathrm{e} / \mathrm{yll}\right.$ olarak) atık suda görülmektedir. $\mathrm{Bu}$ verilere göre Adıyaman ilindeki tekstil fabrikanın Toplam KAİ miktarı yaklaşık olarak 297,343 ton $\mathrm{CO}_{2} /$ yll olarak bulunmuştur. Literatür ile kıyaslandığında bu değerlerin kabul edilebilir olduğu görülmekle birlikte çevresel olarak değerlendirildiğinde ise düşürülmesi hem sera gazları açısından hem de yeşil bir dünya için daha kabul edilebilir olması sağlanmış olacaktır.

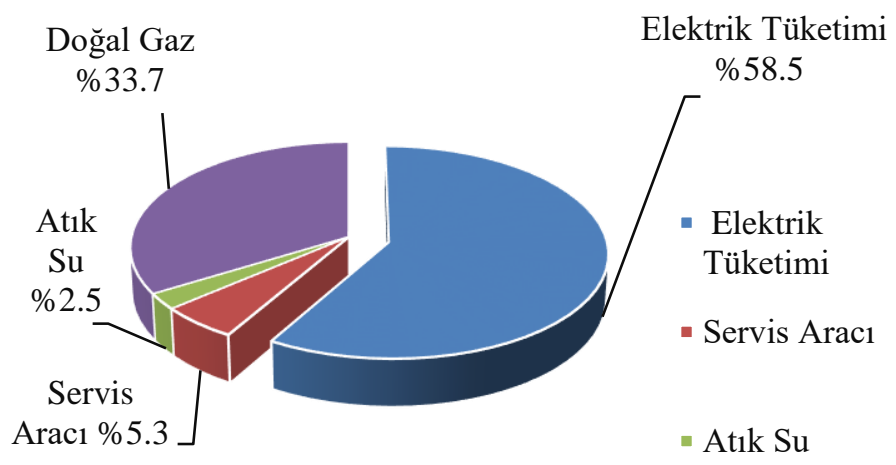

- Doğal Gaz

Şekil 1. Emisyon kaynaklarına göre oluşabilecek yıllık yaklaşık KAI için yüzdesel dağıllımı

Şekil 1'de görüleceği üzere, tekstil fabrikasındaki ürün imalatı süresinde KAI' yi etkileyen en önemli etkinin elektrik tüketiminin olduğu görülmektedir. Etkileyen diğer faktörlerin KAİ'ye etkisi sırasıyla doğal gaz, servis aracının dizel tüketimi ve atık sudur. Tekstil fabrikalarının KAİ değerlendirmesine dair yapılan bu çalışma hem Türkiye genelinde hem Adıyaman ilinde özel ve önemli bir yer teşkil etmektedir. Bahsi geçen tekstil fabrikasının KAİ miktarına en yüksek etkinin, sonuçlardan da anlaşıldığı üzere elektrik tüketimi ve doğal gazdan kaynaklı emisyonları azaltmaya çalışmak hem belirtilen fabrika için hem de tekstil sektöründeki yeni üretimciler için büyük önem arz etmektedir. Elektrik ve doğal gaz tüketimi toplamın yaklaşık olarak 92\%'sini oluşturduğu için bu bağlamda elektrik tüketimini azaltmak KAİ'ye önemli bi etki yapacaktır. Atık su ve Servis aracı (fosil yakıt tüketimi) toplamın yaklaşık $8 \%$ ' sini oluşturmakla birlikte belirtilen değer literatür ile kıysalandığında oldukça kabul edilebilir düzeydedir.

\section{Kaynakça}

Akhtar, S., Baig, S. F., Saif, S., Mahmood, A., \& Ahmad, S. R. (2017). Five Year Carbon Footprint of a Textile Industry: A Podium to incorporate Sustainability. Nature Environment and Pollution Technology, 16(1), 8.

Athalye, A. (2012). Carbon footprint in textile processing. Colourage, 59(12), 45-47

Başoğul, Y., \& Göksu, T. T. (2021). Carbon Foot Print Evaluation of an Industrial Enterprise Producing Flour: A Case study of Adiyaman Province. MAS Journal of Applied Sciences, 7(7). https://doi.org/10.52520/masjaps.40

Bevilacqua, M., Ciarapica, F. E., Giacchetta, G., \& Marchetti, B. (2011). A carbon footprint analysis in the textile supply chain. International Journal of Sustainable Engineering, 4(1), 24 36. https://doi.org/10.1080/19397038.2010.502582 Brander, M. (2012) Greenhouse gases, CO2, CO2e, and carbon: What do all these terms mean? Ecometrica.

Brander, M. (2012) Greenhouse gases, CO2, CO2e, and carbon: What do all these terms mean? Ecometrica.

Eggleston, S., Buendia, L., Miwa, K., Ngara, T., \& Tanabe, K. (2006). IPCC guidelines for national greenhouse gas inventories.

Gülhan, H., Özgün, H., Erşahin, M. E., Dereli, R. K., \& Öztürk, İ. (2018). İstanbul'daki Biyolojik Atıksu Arıtma Tesislerinin Sera Gazı Emisyonunun Modelleme Metodu ile Tahmini. Frrat Üniversitesi Mühendislik Bilimleri Dergisi, 30(1), 5967.

Huang, B., Zhao, J., Geng, Y., Tian, Y., \& Jiang, P. (2017). Energy-related GHG emissions of the textile industry in China. Resources, Conservation and Recycling, 119, 69-77. https://doi.org/10.1016/j.resconrec.2016.06.013

Jain, M. (2017). Ecological approach to reduce carbon footprint of textile industry. 11.

JRC, EC. (2007). Carbon Footprint: What it is and how to measure it. European Platform on Life Cycle Assessment European Commission, Joint

Muthu, S. S., Li, Y., Hu, J. Y., \& Ze, L. (2012). Carbon footprint reduction in the textile process chain: Recycling of textile materials. Fibers and Polymers, 13(8), 1065-1070. https://doi.org/10.1007/s12221-012-1065-0

Oruk, G. \& Baran, M.F (2021). Measurıng Of Carbon Footprint Of Agricultural Economics Students. In book: AgriculturalResearches-Resourcebook, İksad Publishing

Payet, J. (2021). Assessment of Carbon Footprint for the Textile Sector in France. 22.

Rathore, D., \& Singh, R. (2019). Carbon and Ecological Footprint of Textile Industry: Application of R3 Strategy to Mitigate the Environmental Effects of Textile Processing Waste. INTERNATIONAL JOURNAL OF PLANT AND ENVIRONMENT, 5(02), 133-136. https://doi.org/10.18811/ijpen.v5i02.11 
Turhan, E., \& Tolunay, D. (2017). TÜRKIYE VE İSTANBUL'DA KENTSEL KATI ATIK KAYNAKLI SERA GAZI SALIMLARININ DEĞERLENDIRILMESİ. 14.

Wang, C., Wang, L., Liu, X., Du, C., Ding, D., Jia, J., Yan, Y., \& Wu, G. (2015). Carbon footprint of textile throughout its life cycle: A case study of Chinese cotton shirts. Journal of Cleaner Production, 108, 464-475. https://doi.org/10.1016/j.jclepro.2015.05.127

Yan, Y., Wang, C., Ding, D., Zhang, Y., Wu, G., Wang, L., Liu, X., Du, C., Zhang, Y., \& Zhao, C. (2016). Industrial carbon footprint of several typical Chinese textile fabrics. Acta Ecologica Sinica, 36(3), 119-125. https://doi.org/10.1016/j.chnaes.2015.09.002

Zamani, B., Svanström, M., Peters, G., \& Rydberg, T. (2015). A Carbon Footprint of Textile Recycling: A Case Study in Sweden: Carbon Footprint of Textile Recycling. Journal of Industrial Ecology, 19(4), 676-687. https://doi.org/10.1111/jiec.12208 